Supplement of

\title{
Physicochemical uptake and release of volatile organic compounds by soil in coated-wall flow tube experiments with ambient air
}

\section{Guo Li et al.}

Correspondence to: Hang Su (h.su@mpic.de) and Min Shao (mshao@pku.edu.cn)

The copyright of individual parts of the supplement might differ from the CC BY 4.0 License. 


\section{Supplemental Information}

Table S.1. Determined VOC desorption rate coefficient and desorption lifetime on the soil sample, during flushing with VOCsfree $\mathrm{N}_{2}$.

\begin{tabular}{|c|c|c|c|c|c|c|c|c|c|c|c|c|c|}
\hline & \multicolumn{13}{|c|}{ VOC species } \\
\hline & $\mathrm{A}$ & B & $\bar{C}$ & $\mathrm{D}$ & $\mathrm{E}$ & $\mathrm{F}$ & $\mathrm{G}$ & $\mathrm{H}$ & I & $\mathrm{J}$ & $\mathrm{K}$ & $\mathrm{L}$ & $\mathrm{M}$ \\
\hline $\begin{array}{c}\text { Desorption rate } \\
\text { coefficient }\left(\times 10^{-3} \mathrm{~s}^{-1}\right)\end{array}$ & - & 0.8 & - & - & 1.6 & 4.3 & 3.7 & 3.0 & 4.1 & 5.6 & 4.8 & - & 3.1 \\
\hline $\begin{array}{l}\text { Desorption lifetime } \\
\text { (min) }\end{array}$ & - & 22.2 & - & - & 10.8 & 3.9 & 4.5 & 5.7 & 4.1 & 3.0 & 3.5 & - & 5.4 \\
\hline
\end{tabular}

A: styrene, B: formaldehyde, C: toluene, D: isoprene, E: acetic acid, F: MVK+MACR, G: acetaldehyde, H: methanol, I: MEK, J: acetone, K: acetonitrile, L: benzene, M: formic acid. The symbol "-” means no detected emissions of this compound from the soil. 
Table S.2. Integrated total amount and average surface flux of each adsorbed or emitted VOC species on soil for the whole measurement period.

\begin{tabular}{lcccccccccccccc}
\hline & \multicolumn{10}{c}{} & \multicolumn{10}{c}{ VOC species } \\
\cline { 2 - 13 } & $\mathrm{A}$ & $\mathrm{B}$ & $\mathrm{C}$ & $\mathrm{D}$ & $\mathrm{E}$ & $\mathrm{F}$ & $\mathrm{G}$ & $\mathrm{H}$ & $\mathrm{I}$ & $\mathrm{J}$ & $\mathrm{K}$ & $\mathrm{L}$ & $\mathrm{M}$ \\
\hline $\begin{array}{l}\text { Integrated total } \\
\text { amount }(\mu \mathrm{g})\end{array}$ & 0.54 & 11.86 & 2.08 & 0.75 & 2.51 & 0.58 & 1.18 & 9.54 & 0.37 & 1.98 & 0.15 & 0.34 & -2.29 \\
\hline $\begin{array}{l}\text { Average surface } \\
\text { flux }\left(\mathrm{nmol} \mathrm{m}^{-2} \mathrm{~s}^{-1}\right)\end{array}$ & 0.001 & 0.047 & 0.003 & 0.001 & 0.005 & 0.001 & 0.003 & 0.036 & 0.001 & 0.004 & 0.0004 & 0.001 & -0.006 \\
\hline
\end{tabular}

A: styrene, B: formaldehyde, C: toluene, D: isoprene, E: acetic acid, F: MVK+MACR, G: acetaldehyde, H: methanol, I: MEK, J: acetone, K: acetonitrile, L: benzene, M: formic acid. Positive values mean soil uptake and negative values mean soil emission. 
Table S.3. Basic physicochemical parameters (at 298 K) of the measured VOC species.

\begin{tabular}{|c|c|c|c|c|c|c|c|c|c|c|c|c|c|c|}
\hline & \multicolumn{14}{|c|}{ VOC species } \\
\hline & A & $\mathrm{B}$ & $\mathrm{C}$ & $\mathrm{D}$ & $E$ & $\mathrm{~F}_{1}$ & $\mathrm{~F}_{2}$ & $\mathrm{G}$ & $\mathrm{H}$ & I & $\mathrm{J}$ & $\mathrm{K}$ & $\mathrm{L}$ & $\mathrm{M}$ \\
\hline $\begin{array}{c}k_{w} \times 10^{3} \\
\left(\mathrm{~cm} \mathrm{~s}^{-1}\right)\end{array}$ & 7.6 & 10 & 4.4 & 4.6 & 4.7 & 3.6 & 3.6 & 3.4 & 3.8 & 1.7 & 1.8 & 2.1 & 1.3 & -2.0 \\
\hline $\begin{array}{c}k_{O H} \times 10^{12} \\
\left(\mathrm{~cm}^{3} \text { molecule }{ }^{-1} \mathrm{~s}^{-1}\right)\end{array}$ & 58 & 9.4 & 5.6 & 100 & $0.74^{\mathrm{a}}$ & 20 & 29 & 15 & 0.94 & 1.2 & 0.17 & $0.049^{\mathrm{b}}$ & 1.2 & $0.37^{\mathrm{a}}$ \\
\hline $\begin{array}{c}k_{O 3} \times 10^{18} \\
\left(\mathrm{~cm}^{3} \text { molecule }{ }^{-1} \mathrm{~s}^{-1}\right)\end{array}$ & 17 & $<0.01$ & $<0.01$ & 13 & $\mathrm{~N}^{\mathrm{c}}$ & 5.2 & 1.2 & $<0.01$ & $<0.01$ & $\mathrm{~N}$ & $<0.01$ & $\leq 0.15^{b}$ & $<0.01$ & $\mathrm{~N}^{\mathrm{c}}$ \\
\hline $\begin{array}{c}H \times 10^{2} \\
\left(\mathrm{~mol} \mathrm{~m} \mathrm{~m}^{-3} \mathrm{~Pa}^{-1}\right)\end{array}$ & 0.33 & 3200 & 0.15 & 0.013 & 5000 & 30 & 6.0 & 15 & 220 & 18 & 25 & 50 & 0.18 & 7000 \\
\hline $\begin{array}{c}P \\
(\mathrm{~mm} \mathrm{Hg})\end{array}$ & 6.4 & 3.89 & 28.4 & 550 & 15.7 & 152 & 155 & 902 & 127 & 90.6 & 231 & 88.8 & 94.8 & 42.6 \\
\hline $\log K_{o w}$ & 3.05 & 0.35 & 2.73 & 2.42 & -0.17 & 0.41 & $0.59^{d}$ & 0.45 & -0.74 & 0.29 & -0.24 & -0.34 & 2.13 & -0.54 \\
\hline
\end{tabular}

A: styrene, B: formaldehyde, C: toluene, D: isoprene, E: acetic acid, $F_{1}$ : MVK, F2: MACR, G: acetaldehyde, $\mathrm{H}$ : methanol, I: MEK, J: acetone, K: acetonitrile, L: benzene, M: formic acid. $k_{w}$ : surface reaction (or wall loss) rate coefficient, $k_{O H}$ : rate coefficient of VOCs reaction with $\mathrm{OH}$ radicals in gas phase, $k_{O 3}$ : rate coefficient of VOCs reaction with $\mathrm{O}_{3}, H$ : Henry's law constant, $P$ : vapor pressure, $K_{\text {ow }}$ : octanol-water partition coefficient. Both $k_{O H}$ and $k_{O 3}$ data refer to Atkinson and Arey (2003), $H$ data refer to Sander (2015), $P$ and $K_{o w}$ data are from https://pubchem.ncbi.nlm.nih.gov/ and Sangster (1989), unless otherwise noted by a: (Dagaut et al., 1988), b: (Harris et al., 1981), c: (Chebbi and Carlier, 1996) and d: (Barratt, 1996). Positive values of $k_{w}$ mean soil uptake and negative values mean soil emission. $\mathrm{N}$ means the values are negligible. 


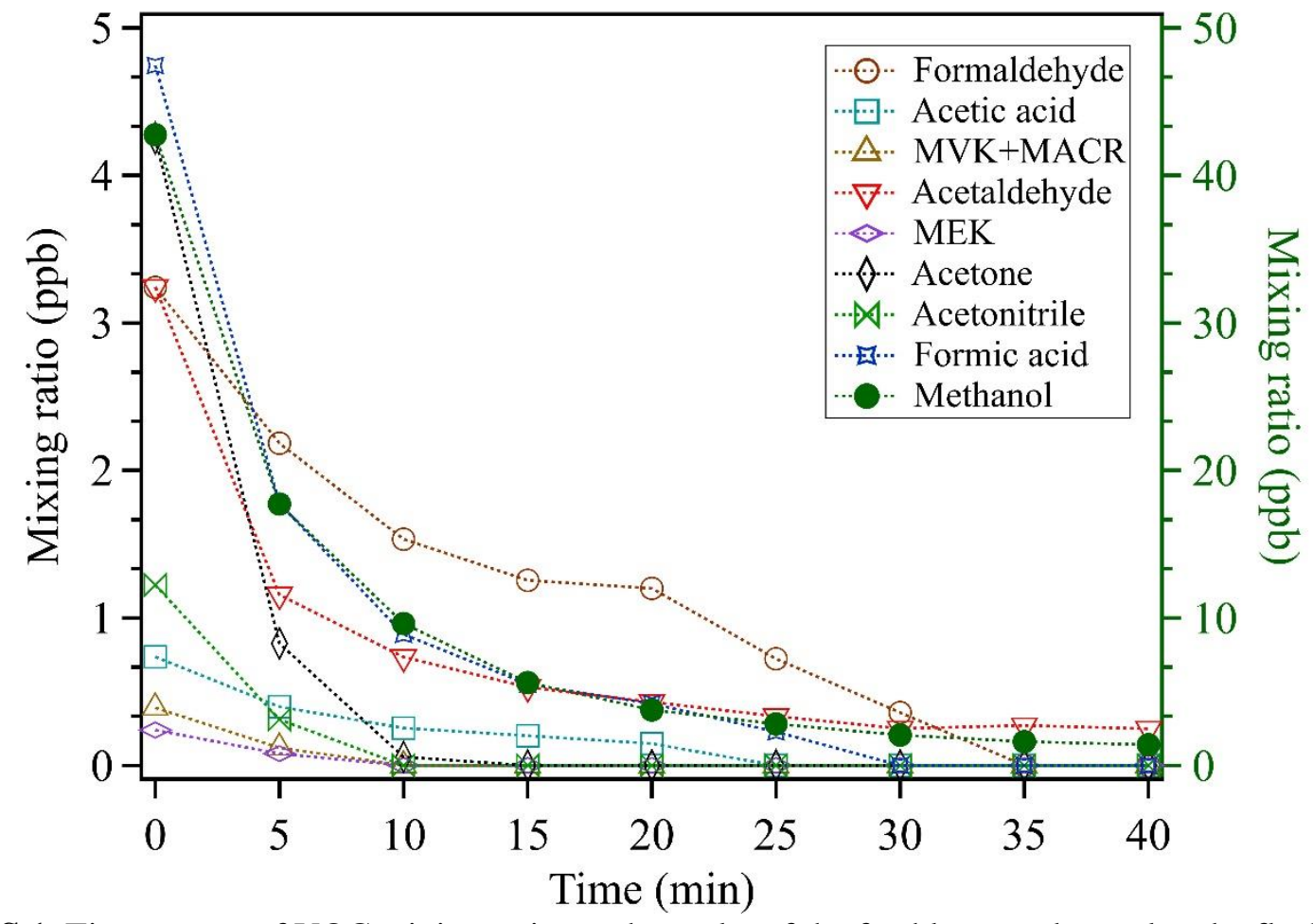

Figure S.1. Time course of VOC mixing ratios at the outlet of the freshly coated sample tube flushed with VOCs-free $\mathrm{N}_{2}$, prior to the ambient air uptake experiment. Methanol mixing ratios are referred to the right vertical axis and the other species are referred to the left. 

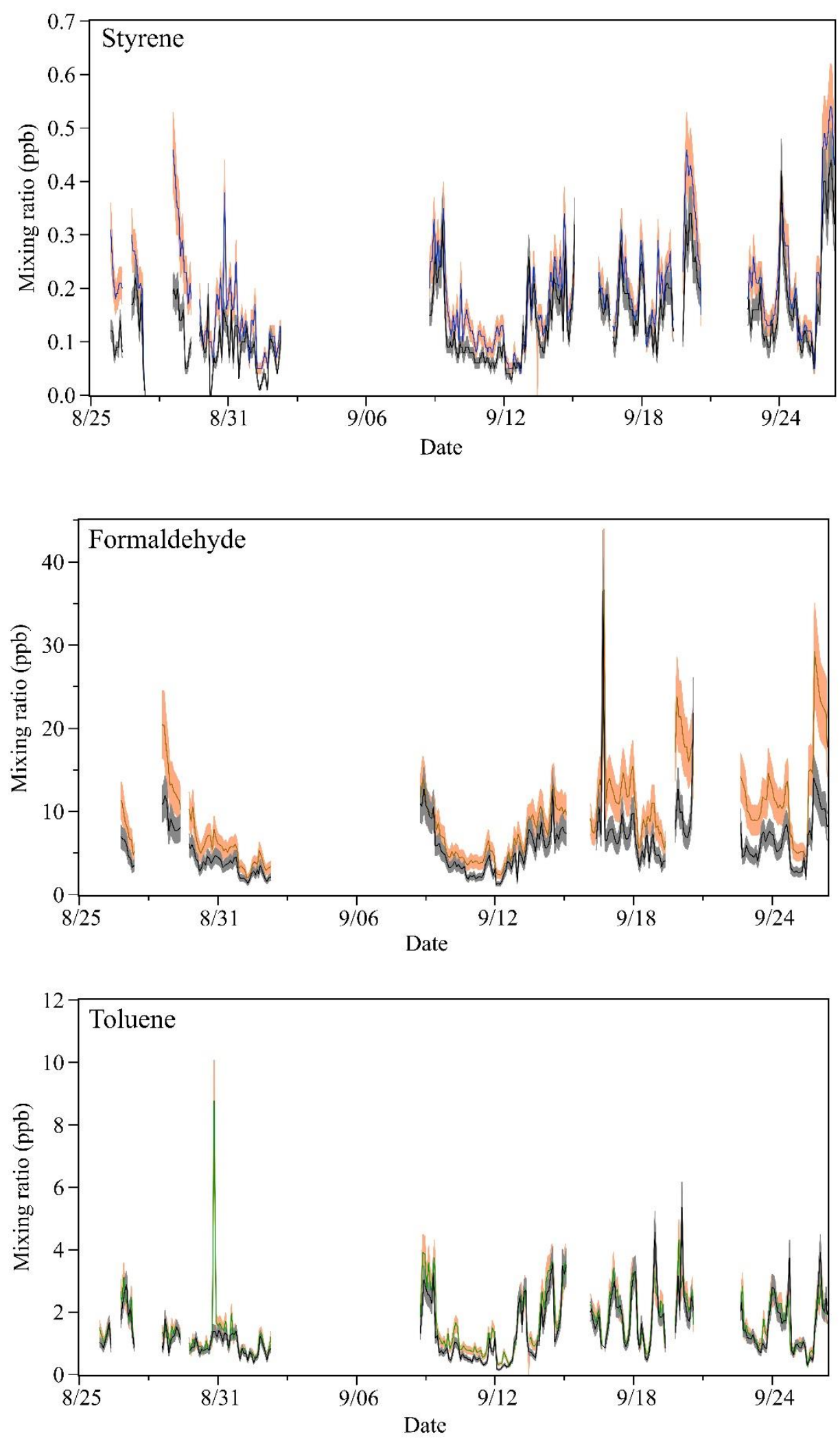

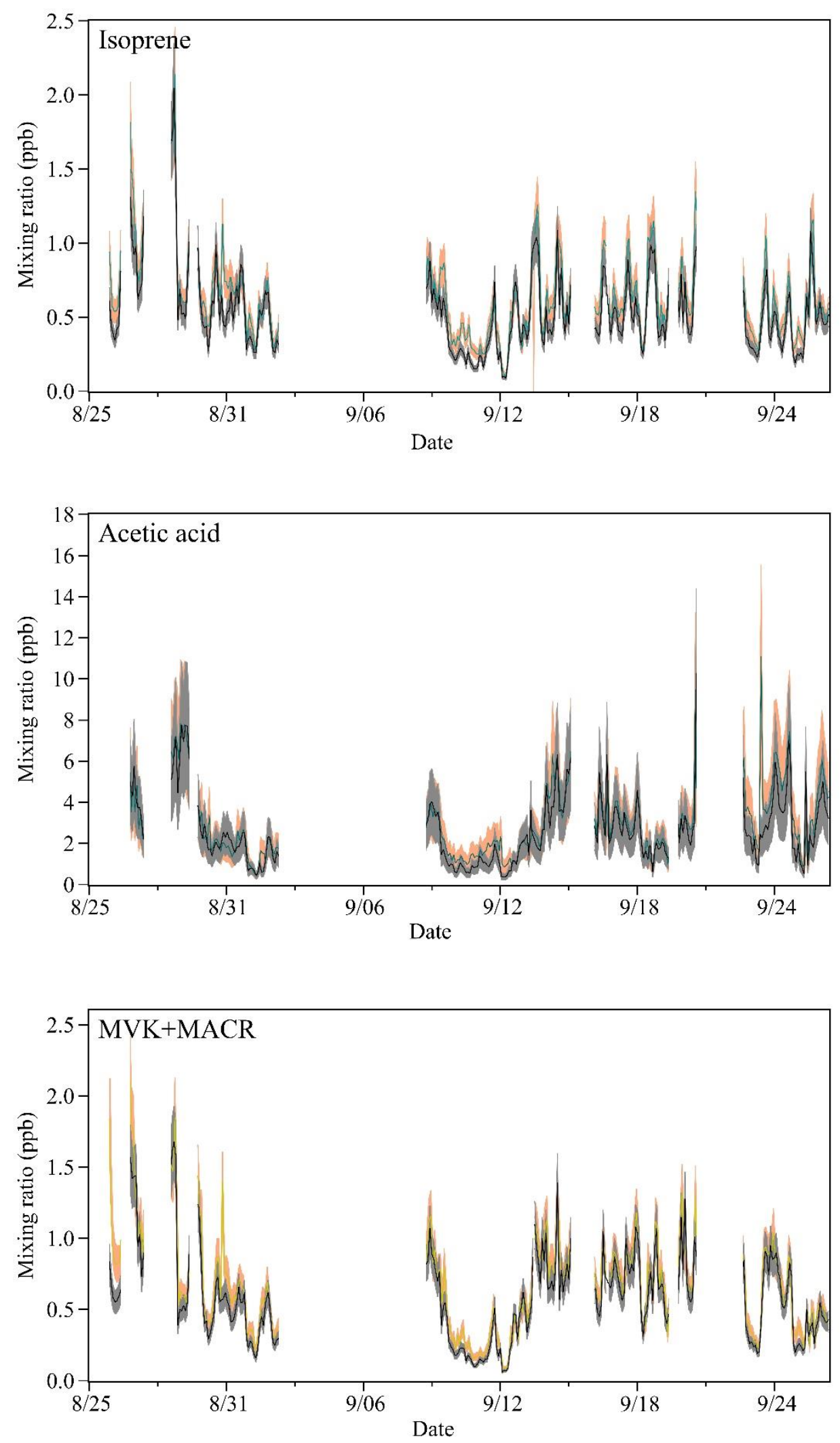

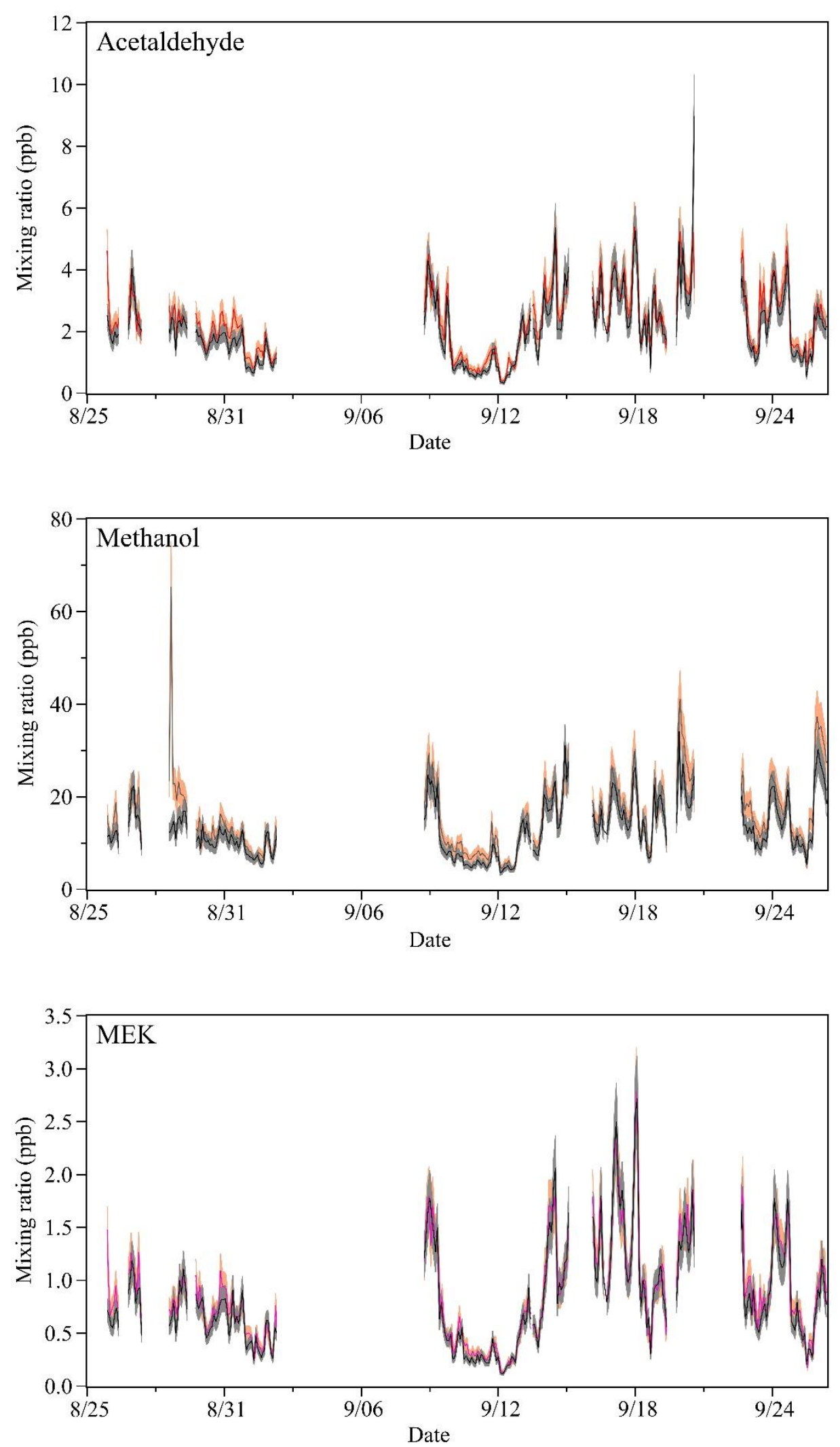

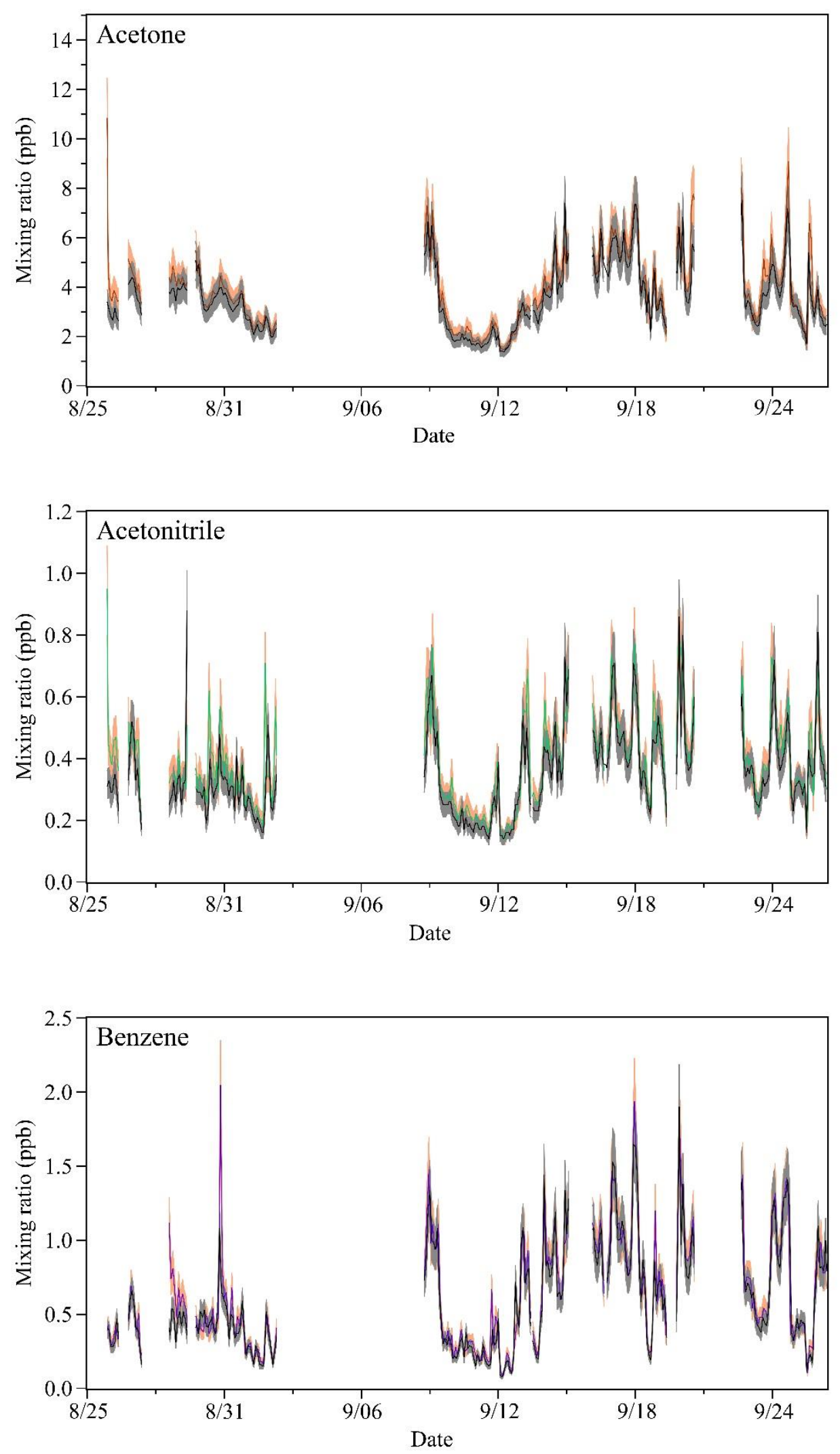


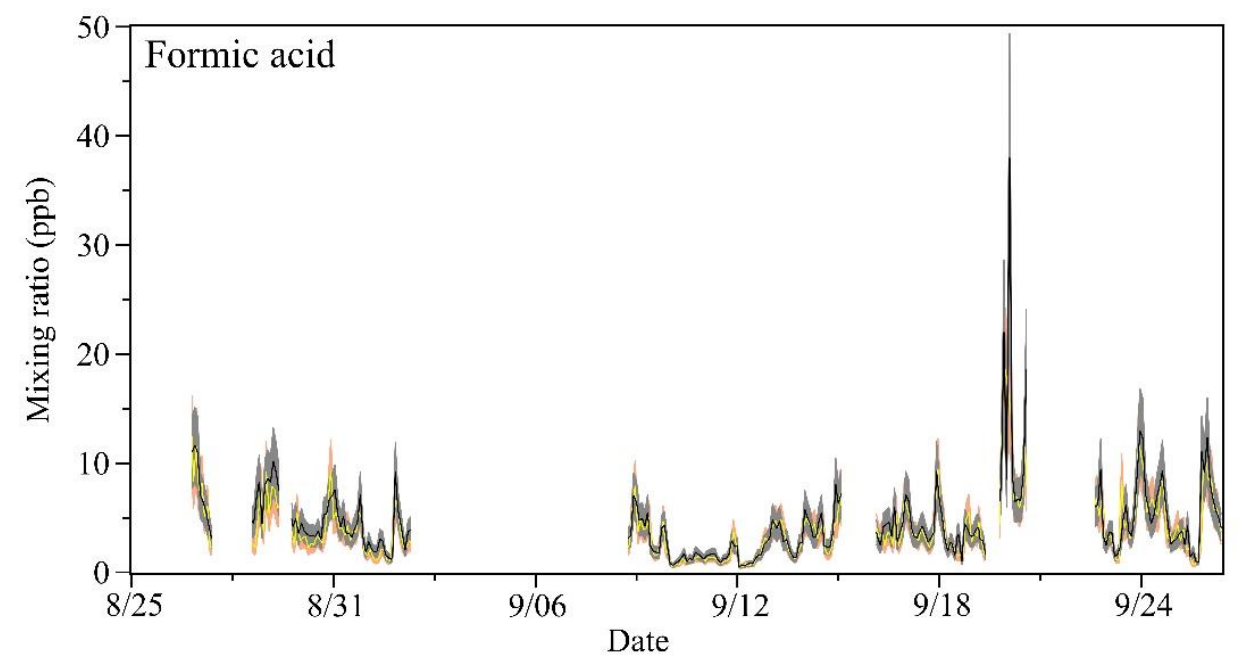

Figure S.2. Time series of ambient air mixing ratios of the examined VOCs. The lines mean the best estimation by the PTR-MS: colorful lines denote $C_{r}$ and black lines denote $C_{s}$. The confidence bands (best estimate \pm measurement uncertainties) are shown as the orange shaded areas (for $C_{r}$ ) and gray shaded areas (for $C_{s}$ ). 

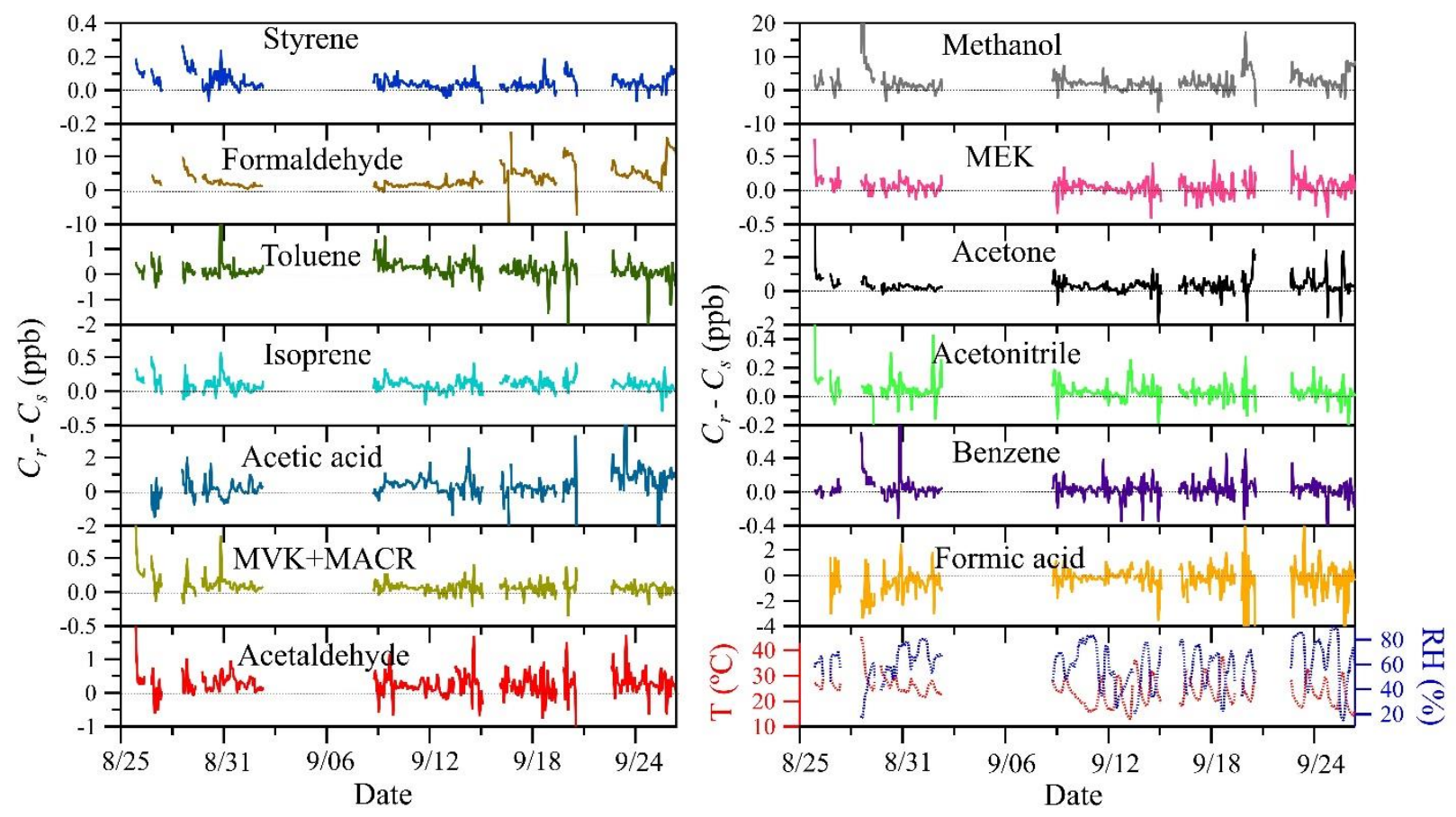

Figure S.3. Time series of the measured VOC mixing ratio differences between the reference channel and the sample channel: $C_{r}-C_{s}$. The lines are plotted using hourly averaged data. 

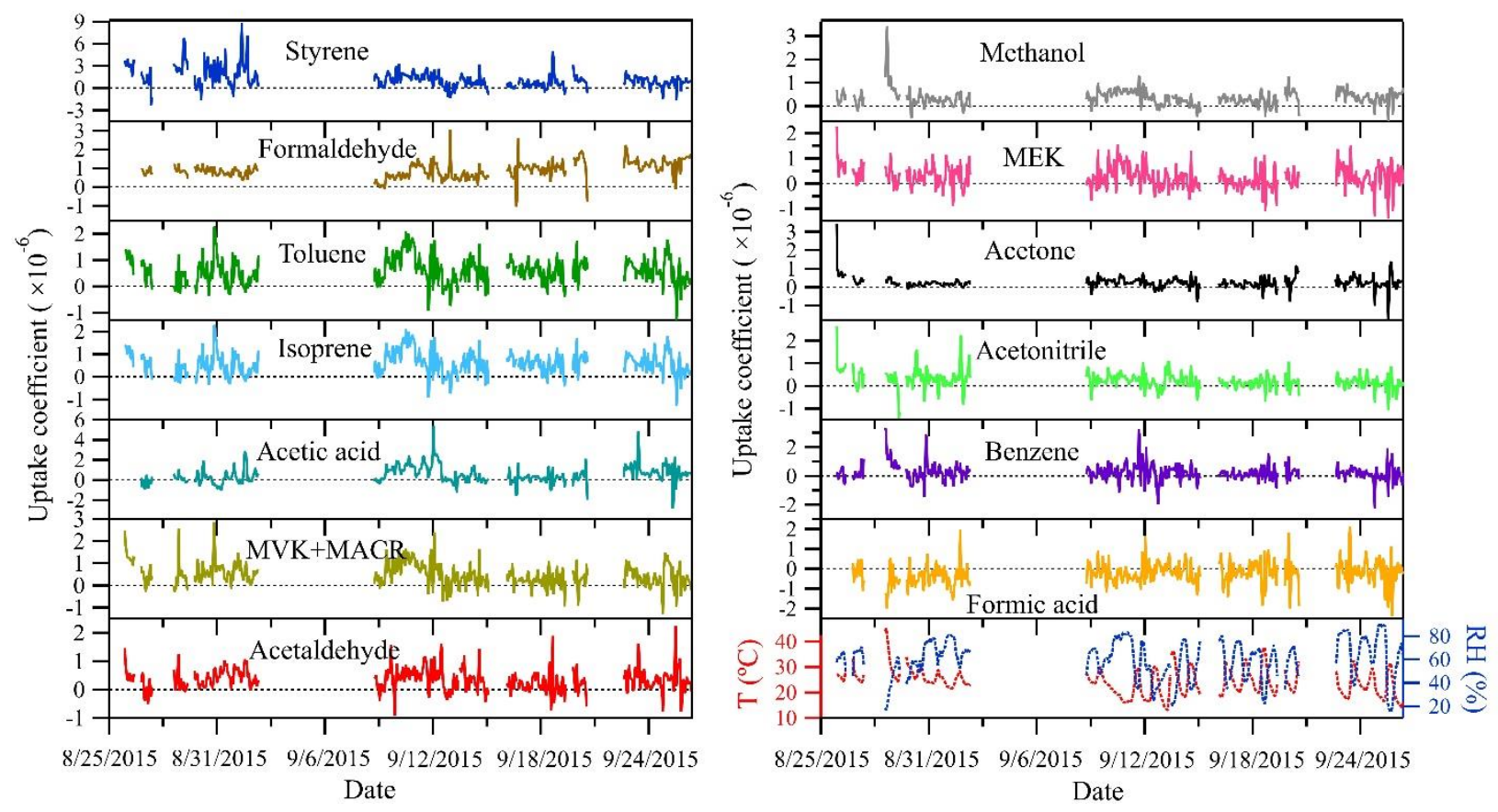

Figure S.4. Time series of the uptake coefficients of measured VOC species. The lines are plotted using hourly averaged data. 

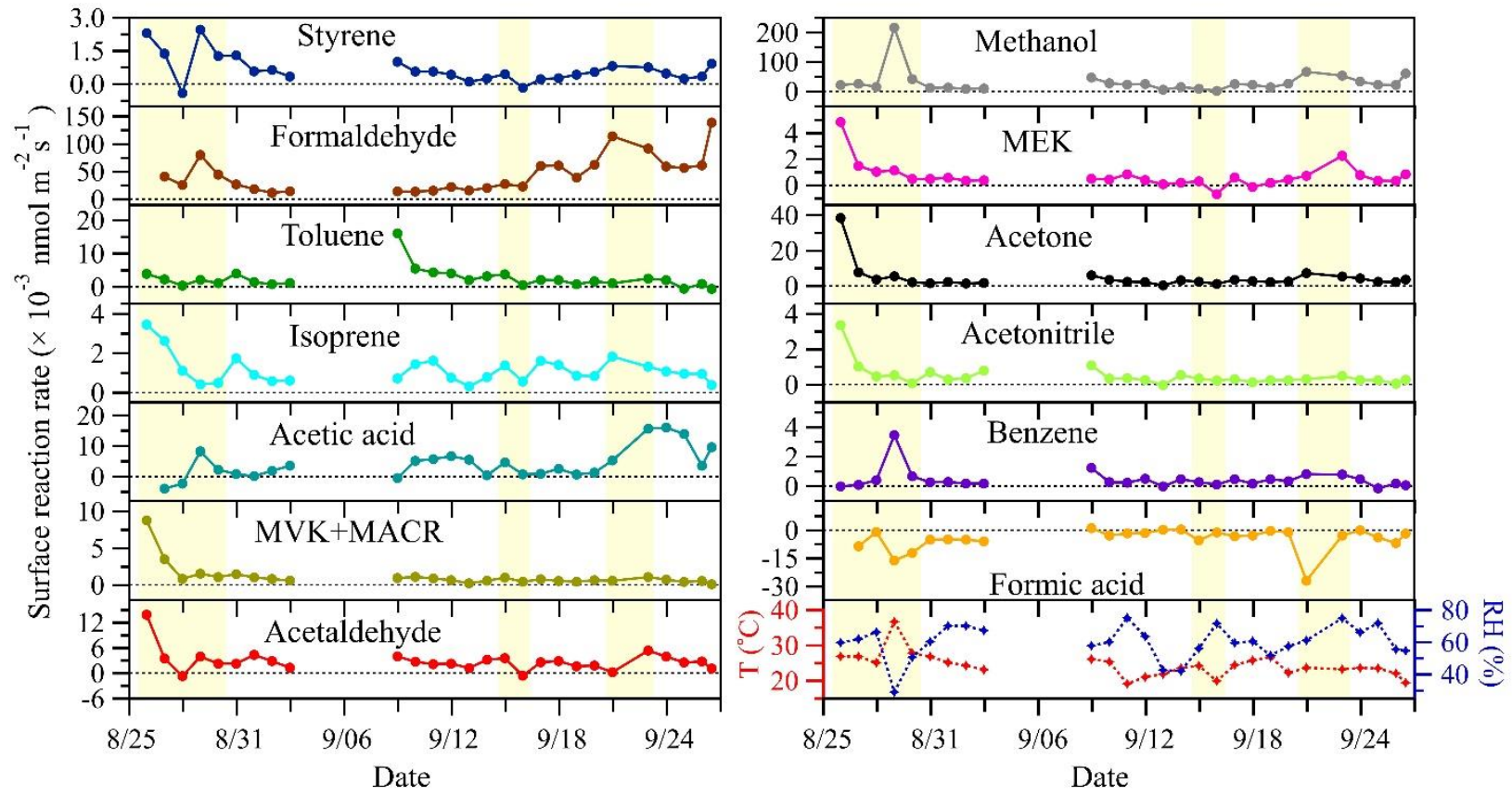

Figure S.5. Time series of the soil surface reaction rate of measured VOC species and air temperature (T) and relative humidity $(\mathrm{RH})$. Each symbol represents daily averaged data and the yellow shaded areas indicate the days when measurements were not continuously running all day long. Positive values mean soil uptake and negative values mean soil emission. At the first three days of the measurement date, the significant decrease of the surface reaction rate for most of the VOC species can be rationalized by combined effect of soil surface adsorption/desorption equilibrium and bulk (soil pores) absorption saturation. 


\section{References:}

Atkinson, R., and Arey, J.: Atmospheric Degradation of Volatile Organic Compounds, Chemical Reviews, 103, 46054638, 10.1021/cr0206420, 2003.

Barratt, M. D.: Quantitative structure-Activity relationships for skin irritation and corrosivity of neutral and electrophilic organic chemicals, Toxicol In Vitro, 10, 247-256, 1996.

Chebbi, A., and Carlier, P.: Carboxylic acids in the troposphere, occurrence, sources, and sinks: A review, Atmospheric Environment, 30, 4233-4249, https://doi.org/10.1016/1352-2310(96)00102-1, 1996.

Dagaut, P., Wallington, T. J., Liu, R., and Kurylo, M. J.: The gas phase reactions of hydroxyl radicals with a series of carboxylic acids over the temperature range 240-440 K, International Journal of Chemical Kinetics, 20, 331-338, doi:10.1002/kin.550200406, 1988.

Harris, G. W., Kleindienst, T. E., and Pitts, J. N.: Rate constants for the reaction of OH radicals with $\mathrm{CH} 3 \mathrm{CN}, \mathrm{C} 2 \mathrm{H} 5 \mathrm{CN}$ AND CH2CH-CN in the temperature range 298-424 K, Chemical Physics Letters, 80, 479-483, https://doi.org/10.1016/0009-2614(81)85061-0, 1981.

Sander, R.: Compilation of Henry's law constants (version 4.0) for water as solvent, Atmos. Chem. Phys., 15, 43994981, 10.5194/acp-15-4399-2015, 2015.

Sangster, J.: Octanol-Water Partition Coefficients of Simple Organic Compounds, Journal of Physical and Chemical Reference Data, 18, 1111-1229, 10.1063/1.555833, 1989. 